\title{
Analysis of Material Loss Behavior According to Long-Term Experiments on LDIE-FAC Multiple Degradation of Carbon Steel Materials
}

\author{
Kyeong Mo Hwang1, Dong Jin Lee', Hun Yun'1, Seung Chang Yoo², Ji Hyeon Kim² \\ ${ }^{1}$ SI Business Department, KEPCO E\&C, Gimcheon-si, Korea \\ ${ }^{2}$ Nuclear Engineering Department, UNIST, Ulsan-si, Korea \\ Email: hkm@kepco-enc.com
}

How to cite this paper: Hwang, K.M., Lee, D.J., Yun, H., Yoo, S.C. and Kim, J.H. (2022) Analysis of Material Loss Behavior According to Long-Term Experiments on LDIE-FAC Multiple Degradation of Carbon Steel Materials. World Journal of Nuclear Science and Technology, 12, 1-10. https://doi.org/10.4236/wjnst.2022.121001

Received: November 25, 2021

Accepted: January 7, 2022

Published: January 10, 2022

Copyright $\odot 2022$ by author(s) and Scientific Research Publishing Inc. This work is licensed under the Creative Commons Attribution International License (CC BY 4.0).

http://creativecommons.org/licenses/by/4.0/

\begin{abstract}
Recently, damage caused by liquid droplet impingement erosion (LDIE) in addition to flow-accelerated corrosion (FAC) has frequently occurred in the secondary side steam piping of nuclear power plants, and the damage-occurring frequency is expected to increase as their operating years' increase. In order to scrutinize its causes, therefore, an experimental study was conducted to understand how the behavior of LDIE-FAC multiple degradation changes when the piping of nuclear power plants is operated for a long time. Experimental results show that more magnetite was formed on the surface of the carbon steel specimen than on the low-alloy steel specimen, and that the rate of magnetite formation and extinction reached equilibrium due to the complex action of liquid droplet impingement erosion and flow-accelerated corrosion after a certain period of time. Furthermore, it was confirmed at the beginning of the experiment that A106 Gr.B specimen has more mass loss than A335 P22 specimen. After a certain period of time, however, the mass loss tends to be the opposite. This is presumed to have resulted from the magnetite formed on the surface playing a role in suppressing liquid droplet impingement erosion. In addition, it was confirmed that the amount of erosion linearly increases under the conditions in which the formation and extinction of magnetite reach equilibrium.
\end{abstract}

\section{Keywords}

Liquid Droplet Impingement Erosion (LDIE), Flow-Accelerated Corrosion (FAC), Multiple Degradations, ToSPACE, Wall Thinning, Magnetite

\section{Introduction}

In general, liquid droplet impingement erosion is a degradation mechanism that 
has occurred a lot in aircraft blades or turbine blades. In recent years, however, a lot of damage has occurred due to liquid droplet impingement erosion even in the secondary side steam piping of nuclear power plants. The reason is that the secondary side steam piping of nuclear power plants is not exposed to $100 \%$ dry steam, and that very fast droplets entrained in steam may give impact on components such as orifice or control valve. When there is a component such as elbow or tee at the downstream of the orifice or control valve, droplets contained in the steam collide with the pipe wall and damage the base material.

In 2000, damages caused by liquid droplet impingement erosion occurred in high-pressure turbine outlet nozzle and low-pressure turbine outlet elbow of Tihange plant, an elbow installed in the feedwater heater vent line of North Anna plant, a pipe downstream of an orifice from the $1^{\text {st }}$ stage reheater of LaSalle plant [1]. In Korea, damages caused by liquid droplet impingement erosion also occurred at a header pipe of the low-pressure feedwater heater vent line of CANDU plant in 2008, an end cap of the $1^{\text {st }}$ stage reheater exhaust line of Westinghouse plant in 2011, and a header pipe downstream of the steam trap of APR-1000 plant in 2016, and all the damaged pipes were replaced. As the number of their operating years' increases, damage caused by liquid droplet impingement erosion is expected to increase further.

Accordingly, to develop a theoretical formula for predicting liquid droplet impingement erosion in the steam piping of nuclear power plants, K. M. Hwang et al. have conducted "Development of a LDIE Prediction Theory in the Condition of Magnetite Formation on Secondary Side Piping in Nuclear Power Plants" [2]. In the LDIE studies conducted by Hattori [3], Heymann [4], and Li [5], the experiments for collision of droplets without the magnetite oxide film formed on the surface were conducted with the base material. In the study of K. M. Hwang et al., an experiment was performed under the same conditions of forming the magnetite oxide film as the inside surface of the secondary side piping of nuclear power plants, and it was confirmed that the LDIE degradation occurring on the pipe surface of the secondary side of nuclear power plants is caused by multiple degradation of flow-accelerated corrosion by the flow of water film and liquid droplet impingement erosion by droplets colliding on the water film. In addition, it was identified that the material loss was large in carbon steel at the beginning of the experiment, but then the material loss occurred more severely in low alloy steel after a certain period of time. These findings were also reflected in the LDIE prediction theory of the ToSPACE program developed by KEPCO E\&C [6]. However, in the experiment conducted for 96 hours in 2016, it was impossible to determine how the material loss behavior changes in case of a long-term experiment. Therefore, this paper describes the results of LDIE experiment performed for 500 hours to understand the material loss behavior of carbon steel and low alloy steel materials with magnetite. The experiment was conducted under the same conditions as the previous experiment except for the water chemistry control facility. 


\section{Experiment Method}

\subsection{Experimental Facility}

The experimental facility used in the study of K. M. Hwang et al. was utilized for long-term LDIE-FAC multiple degradation experiment. However, only the water chemistry concentration control facility for $\mathrm{pH}$ was partially changed. The experimental facility was designed according to the Rotating Disk Method presented in ASTM G73-10 [7].

The rotating disk method is that the rotating test specimens are placed at outer circle with the sprayed droplets from nozzle. And, this method can easily adjust the colliding velocity with the droplets by controlling the velocity of the disk rotation. And it can easily measure the size of droplets using an ultrahigh-speed camera. On the other hand, it takes time to damage the specimen due to a relatively low frequency of collision compared to that of using the water jet method. Figure 1 shows the schematic diagram of the experimental facility for replication of LDIE-FAC multiple degradations. The experimental facility consists of the water treatment equipment and the rotating disk-and-droplet repetitive impact

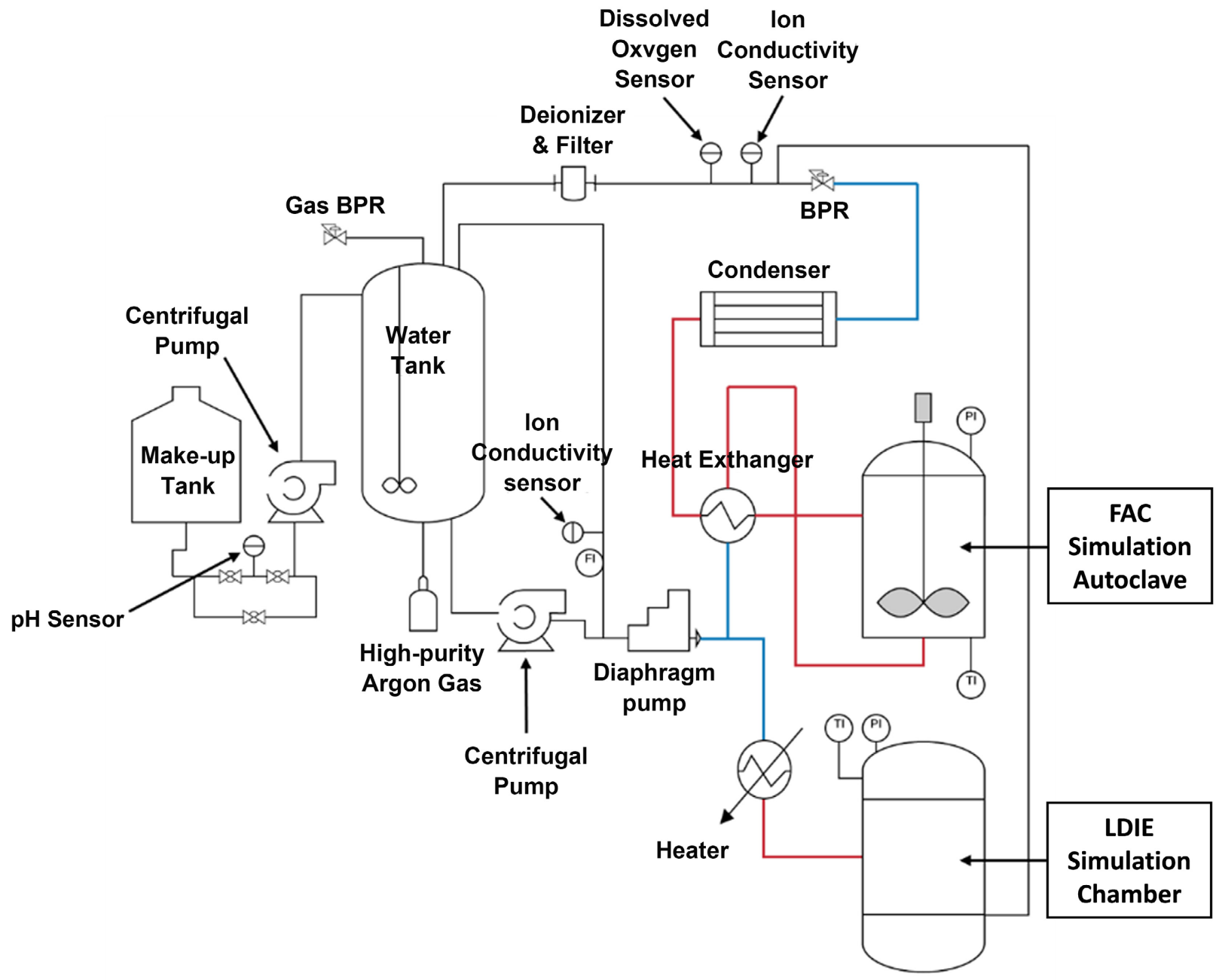

Figure 1. Schematic diagram of the experimental facility. 
apparatus. The water treatment equipment can generate the magnetite on the surface of the specimens by adjusting temperature, amine concentration and dissolved oxygen. A nozzle for generating the liquid droplets and eight test pieces for testing several specimens at the same time were equipped in the rotating apparatus. The water chemistry balancing tanks and the rotating disk-and-droplet repetitive impact apparatus are shown in Figure 2 and Figure 3.

\subsection{Experiment}

A long-term LDIE-FAC multiple degradation experiment was performed under the same conditions as the previous study except for the water chemistry control facility [2]. Test specimens were manufactured in a size of $10 \times 30 \mathrm{~mm}^{2}$ for two types of materials, such as A106 Gr.B (carbon steel) and A335 P22 (low alloy steel), and were placed at outer circle of the experimental facility after undergoing diamond paste pretreatment, ultrasonic washing and initial mass measurement. The experimental conditions are as follows:

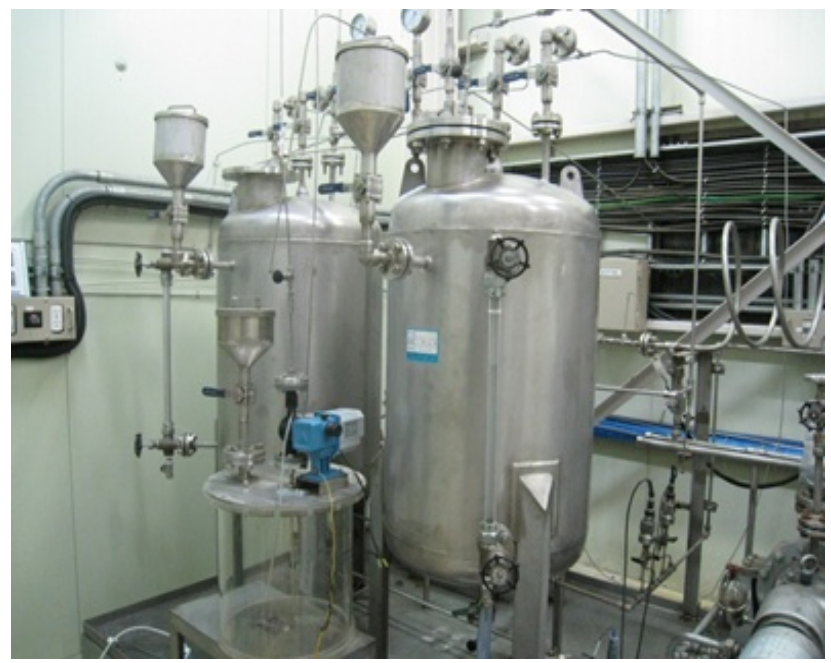

Figure 2. Water chemistry balancing tank.

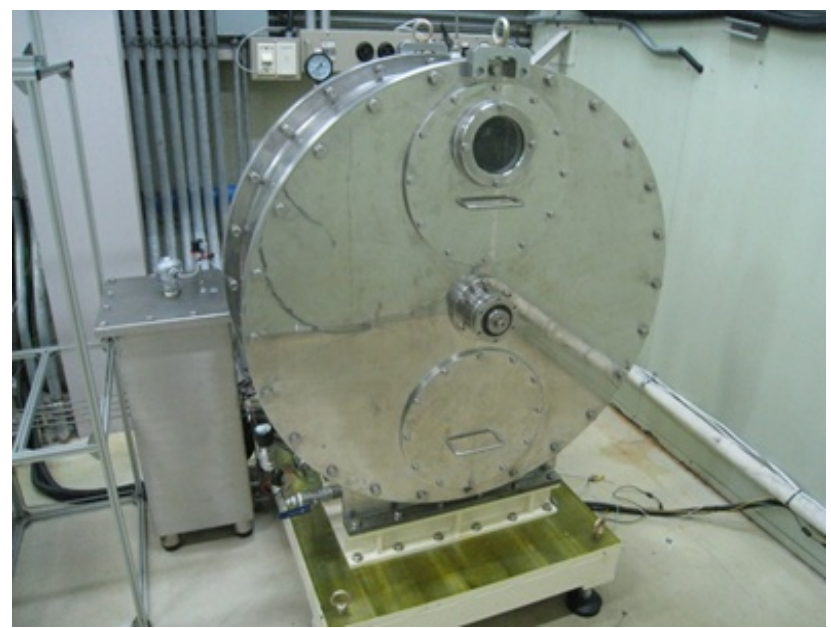

Figure 3. LDIE simulation rotating apparatus. 
- Temperature: $30^{\circ} \mathrm{C}$;

- Colliding velocity: $120 \mathrm{~m} / \mathrm{s}$;

- Average droplets size: $600 \mu \mathrm{m}$;

- Dissolved oxygen: <5 ppb;

- pH: 4;

- Experimental duration: 500 hours.

Experimental fluid was maintained at $\mathrm{pH} 4$ by diluting the nitric acid solution in ultrapure water. In the previous study, the dissolved hydrogen concentration and dissolved oxygen concentration were adjusted using hydrogen. However, the electrochemical potential is hardly changed depending on the dissolved hydrogen concentration in an environment with low dissolved oxygen concentration, and in this experiment, the dissolved hydrogen concentration was adjusted using argon gas instead of hydrogen for safety [8].

Four specimens of two materials, A106 Gr.B and A335 P22, were each placed at outer circle of the rotating disk, and experiment was performed. The mass of each specimen was initially measured every 24 hours to stabilize the experiment, and in the second half of the experiment, was measured at the time of every 100 hours to conduct the experiment rapidly. Mass measurement was done by the method presented in ASTM G73-10 "Standard Test Method for Liquid Impingement Erosion Using Rotating Apparatus" [7].

\section{Experimental Results}

\subsection{Results of Surface Observation}

To observe the damage behavior of the specimen surface due to LDIE-FAC multiple degradations, the surface was observed with an optical microscope whenever the specimens were drawn out. Figure 4 shows the optical microscope photographs of continuously observing the surface by selecting each one of A106 Gr.B and A335 P22 specimens.

At the time of 24 hours after the start of the experiment, black oxide film (magnetite) was formed on the surfaces of both specimens, while erosion characteristics were not shown. Between 96 and 300 hours, more magnetite was formed on the surface of the specimens and traces of erosion damage began to appear, although visual observation was difficult. Judging from the darker surface of A106 Gr.B specimen in the optical microscope photograph, it was discovered that more magnetite was produced on A106 Gr.B specimen than A335 P22 specimen. At the time of 400 hours, it was found in A335 P22 specimen that the erosion progressed enough to be visually confirmed and the color of the surface began to brighten. This is presumed to have resulted from the magnetite formed on the surface, which is eroded and reproduced repeatedly. In A106 Gr.B specimen, on the other hand, such damage in the A335 P22 specimen has not yet appeared. At the time 500 hours, it was found that erosion occurred enough to be visually observed in A106 Gr.B specimen. The reason why this phenomenon appeared in A106 Gr.B specimen later than A335 P22 specimen is estimated to 


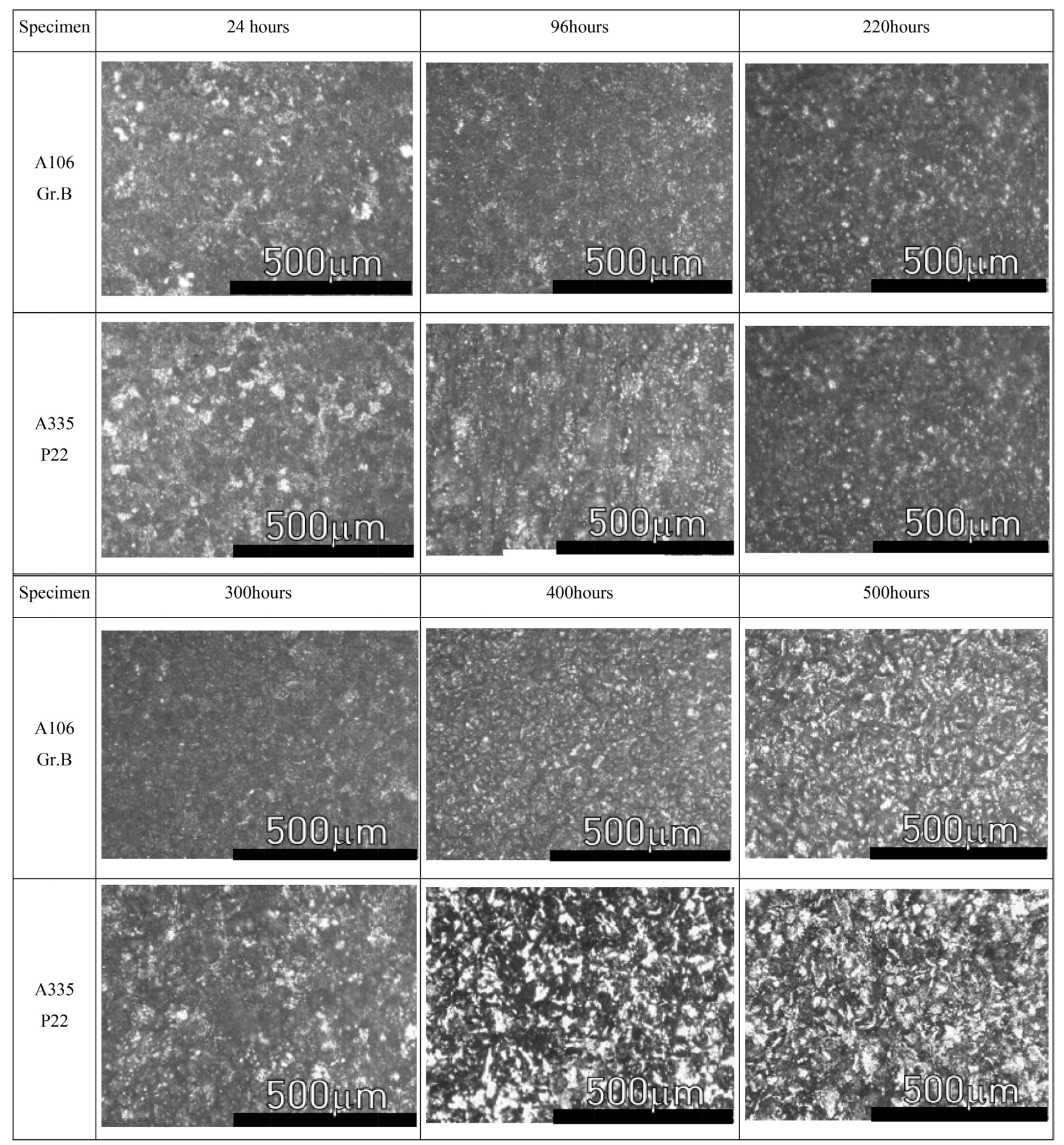

Figure 4. Optical microscope photographs according to experimental time for A106 Gr.B and A335 P22 specimens.

be that the magnetite formed on the surface played a protecting role from being damaged by LDIE. In addition, it was confirmed that the surface shape and the degree of magnetite formation of A335 P22 specimen were similar at 400 hours and 500 hours. Accordingly, it is estimated that the formation and extinction of magnetite have reached equilibrium after erosion has progressed to some extent. Similar phenomenon is also observed in A106 Gr.B specimen. Figure 5 shows the snapshots before and after 300 hour-experiment for A106 Gr.B and A335 


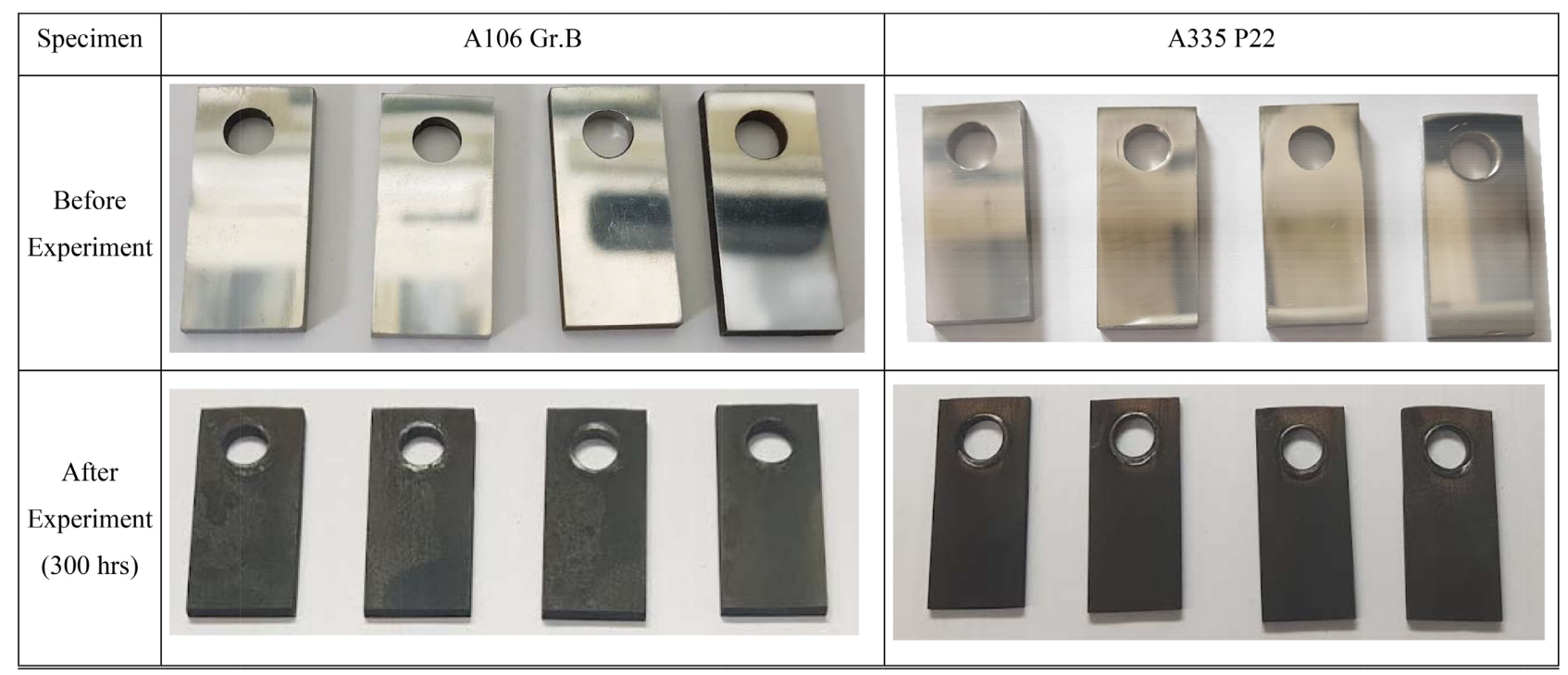

Figure 5. Snapshots before and after 300 hour-experiment for A106 Gr.B and A335 P22 specimens.

P22 specimens. It can be confirmed that black oxide film is formed on all specimens, but it is difficult to visually identify the damaged state. Figure 6 shows the optical microscope photographs taken by magnifying with $50 \mu \mathrm{m}$ on the surfaces of the two specimens at the time of 500 hours. In A335 P22 specimen, cracks occurred and particles fell off, whereas cracks did not appear in A106 Gr.B specimen. It is presumed that the magnetite formed more on the surface of A106 Gr.B specimen than A335 P22 specimen suppressed cracking.

\subsection{Mass Loss Behavior}

In order to observe the mass loss behavior of A106 Gr.B specimen and A335 P22 specimen due to LDIE-FAC multiple degradations, the mass of each specimen was measured whenever the specimen was withdrawn. Figure 7 shows the average mass loss over time of the four specimens for each material. Until about 170 hours after the start of the experiment, A106 Gr.B specimen had more mass loss than A335 P22 specimen, but the mass loss reversed from 170 hours after the start of the experiment. This phenomenon is presumed to be due to more active formation and dissolution of magnetite in A106 Gr.B specimen at the beginning of the experiment than in A335 P22 specimen.

From about 170 hours after the start of the experiment, the difference in mass loss between A106 Gr.B and A335 P22 specimens gradually increased, and after about 250 hours, it was found that the mass loss of both A106 Gr.B and A335 P22 specimens increased almost linearly. The mass loss rate for A106 Gr.B and A335 P22 materials in the condition of average droplets size $600 \mu \mathrm{m}$, colliding velocity $120 \mathrm{~m} / \mathrm{s}, \mathrm{pH} 4$, and $30^{\circ} \mathrm{C}$ can be expressed as follows:

below 250 hours

$$
\begin{aligned}
& \dot{m}=1.0 \times 10^{-6} t^{4}-0.0005 t^{3}+0.82 t^{2}-0.92 t+2.41 \quad(\mathrm{~A} 106 \mathrm{Gr} . \mathrm{B}) \\
& \dot{m}=1.0 \times 10^{-6} t^{4}-0.0007 t^{3}+0.09 t^{2}-0.08 t-3.76 \quad(\mathrm{~A} 335 \mathrm{P} 22)
\end{aligned}
$$



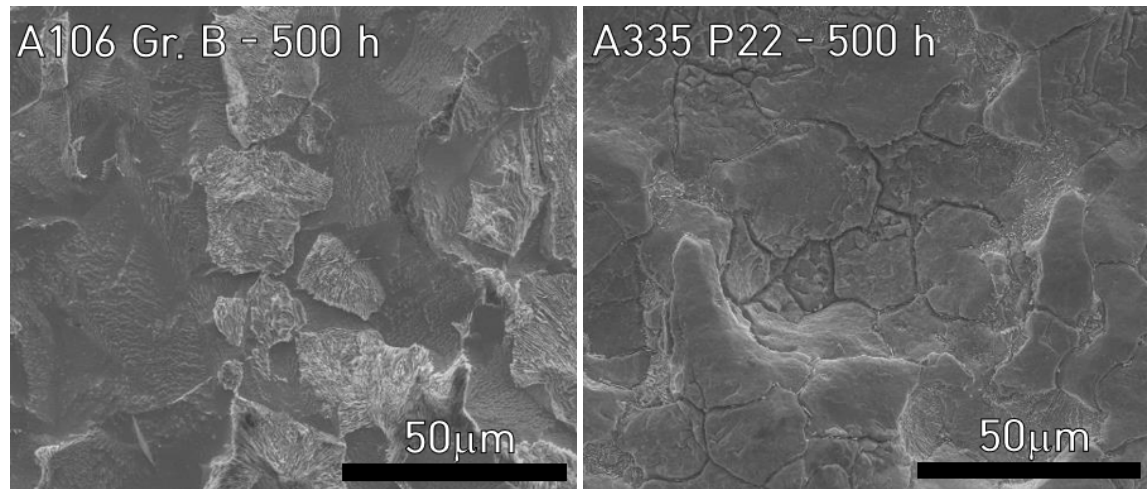

Figure 6. Optical microscope photographs for A106 Gr.B and A335 P22 specimens at 500 hours.

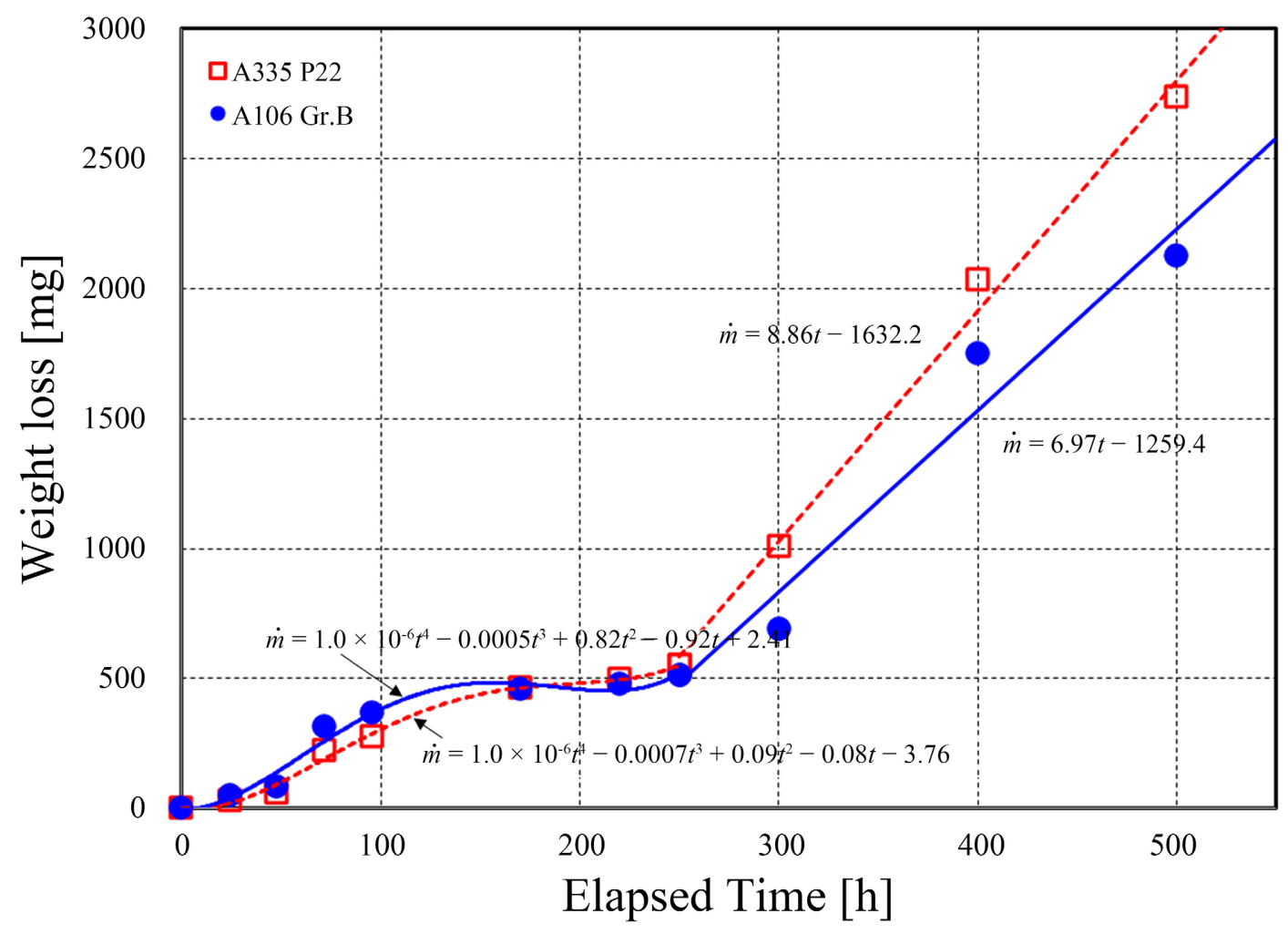

Figure 7. Mass loss behavior according to experimental time for A106 Gr.B and A335 P22 specimens.

over 250 hours

$$
\begin{gathered}
\dot{m}=6.97 t-1259.4 \quad(\mathrm{~A} 106 \mathrm{Gr} . \mathrm{B}) \\
\dot{m}=8.86 t-1632.2 \quad(\mathrm{~A} 335 \mathrm{P} 22)
\end{gathered}
$$

where, $\dot{m}$ : mass loss rate $(\mathrm{mg} / \mathrm{h}) ; t$ : operating time $(\mathrm{h})$.

As a result, it is estimated that the effect of FAC in this experimental condition was dominant up to about 170 hours, and the effect of LDIE played more influential role on mass loss than the FAC effect thereafter. This reversal of mass loss between A106 Gr.B and A335 P22 specimens was similar to the previous study by K. M. Hwang et al. [2]. 


\section{Conclusion}

Recently, damage due to liquid droplet impingement erosion has frequently occurred in the secondary side steam piping of nuclear power plants, and the damage frequency is expected to increase further as the number of their operating years' increases. In 2016, a 96-hour short-term experiment was conducted, whereas a 500-hour experiment was performed in this study to analyze how the damage behavior changes when A106 Gr.B and A335 P22 materials are exposed to the environment of liquid droplet impingement for a long time. As a result of observing the surface of the experimental specimens with an optical microscope, it was confirmed that more magnetite was formed on the surface of the carbon steel specimen than on the low alloy steel specimen, and that the rate of magnetite formation and extinction reached equilibrium after a certain period of time. As a result of analyzing the mass loss amount, it was confirmed that A106 Gr.B specimen has a larger mass loss amount than A335 P22 specimen at the beginning of the experiment, but the mass loss rate tends to be opposite after a certain period of time. This is presumed to be because the magnetite formed on the surface of specimen plays a dominant role in suppressing liquid droplet impingement erosion damage. As a result, LDIE damage occurring in the operating environment is presumed to be due to the multiple degradations of LDIE and FAC. Also, it is confirmed that erosion linearly increases under the condition where magnetite formation and extinction reach equilibrium.

\section{Conflicts of Interest}

The authors declare no conflicts of interest regarding the publication of this paper.

\section{References}

[1] EPRI (2004) Recommendations for Controlling Cavitation, Flashing, Liquid Droplet Impingement, and Solid Particle Erosion in Nuclear Power Plant Piping Systems, 1011231. Final Report.

[2] Hwang, K.M., Seo, H.K., Lee, C.K. and Nam, W.C. (2017) Development of a LDIE Prediction Theory in the Condition of Magnetite Formation on Secondary Side Piping in Nuclear Power Plants. World Journal of Nuclear Science and Technology, 7, 1-14. https://doi.org/10.4236/wjnst.2017.71001

[3] Hattori, S. and Kakuichi, M. (2013) Effect of Impact Angle on Liquid Droplet Impingement Erosion. Wear, 298-299, 1-7. https://doi.org/10.1016/j.wear.2012.12.025

[4] Heymann, F.J. (1969) High-Speed Impact between a Liquid Drop and a Solid Surface. Journal of Applied Physics, 40, 5113-5122. https://doi.org/10.1063/1.1657361

[5] Li, R., Ninokata, H. and Mori, M. (2011) Parametric Investigation on the Effect Factors for Liquid Droplet Impingement Erosion. Proceedings of ASME-JSME-KSME 2011 Joint Fluids Engineering Conference, Shizuoka, Japan, 24-29 July 2011, 1347-1355. https://doi.org/10.1115/AJK2011-03034

[6] Hwang, K.M., Yun, H., Seo, H.K., Lee, G.Y. and Kim, K.W. (2019) Development of ToSPACE for Pipe Wall Thinning Management in Nuclear Power Plants. World Journal of Nuclear Science and Technology, 9, 1-15. 
https://doi.org/10.4236/wjnst.2019.91001

[7] ASTM G73-10 (2017) Standard Test Method for Liquid Impingement Erosion Using Rotating Apparatus.

[8] Higashi, Y., Narabayashi, T., Shimazu, Y., Tsuji, M., Ohmori, M. and Tezuka, K. (2009) Study on Pipe Wastage Mechanism by Liquid Droplet Impingement Erosion. Proceedings of the 17 th International Conference on Nuclear Engineering, Brussels, Belgium, 12-16 July 2009, 1021-1027. https://doi.org/10.1115/ICONE17-76029 